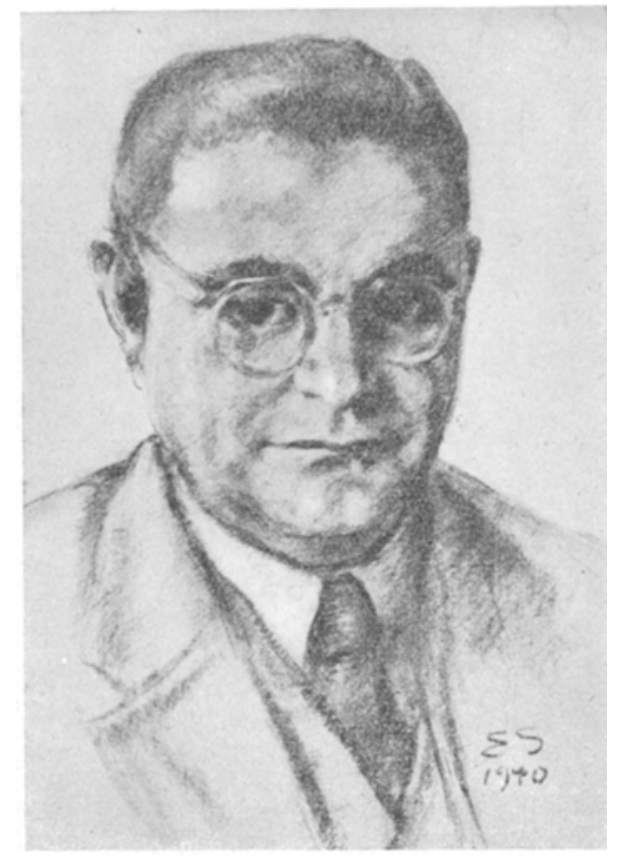

\title{
ARTHUR IMHAUSEN
}

Am 19. Juli 1951 starb in Witten an der Ruhr der Gründer und Senior-Chef der Imhausen-Werke, Arthur Imh ausen, an einer Lungenentzündung. Er wurde am 8. Januar 1885 in Gelsenkirchen geboren. Schon frühzeitig beschäftigte er sich, angeregt durch die Drogen und Chemikalien in der väterlichen Drogerie, mit chemischen Versuchen. So war es kein Wunder, daß die Liebe zur Chemie später so groß wurde, $\mathrm{daB}$ er sich aus der Drogerie herausgezogen fühlte und nach Berlin ging, um dort naturwissenschaftliche Studien zu betreiben, wo er sein Examen als Nahrungsmittelchemiker ablegte. Die Fette interessierten ihn besonders, und von diesen zur Seife war kein großer Schritt mehr. Im Jahre 1912 übernahm er eine kleine Seifenfabrik in Witten und baute diese im Laufe der Zeit zu einem Großunternehmen aus.

Nachdem es gelungen war, hydrierte Fette großtechnisch zu erzeugen, beschäftigte er sich intensiv mit diesen und erkannte deren Vorteil, aber auch die Grenzen bei der Verwendung zu Seifen, Er überlegte frühzeitig, daß er die Eigenschaften der reinen Seifen kennen müsse, wolle er über die technischen Seifen Genaueres aussagen. Er arbeitete hierüber und veranlaßte Zsigmondy in Göttingen, umfangreiche Versuche anzustellen. Aus dieser Zusammenarbeit erwuchs eine enge Freundschaft. Bei einem so klassischen Kolloid wie die Seife war es kein Wunder, daß Arthur Imhausen zu den Mitbegründern der KolloidGesellschaft inLeipzig gehörte. Mit führendenWissenschaftlern, wie Wo. Ostwald, A. Lottermoser, R. E. Liesegang, M. H. Fischer und vielen anderen verband ihn ein reger Gedankenaustausch. Im Jahre 1935 wurde er mit dem Laura R. Le onard-Pre is der Kolloid-Gesellschaft ausgezeichnet

Die Bedeutung von Arthur Im $\mathrm{m}$ a u s en ist nicht besser wiederzugeben als mit den Worten von Wo. Ost wald bei der Úbergabe des Leonard-Preises: „Sie haben mit dem Altmeister der Kolloid-Forschung, Richard Zsigm ond y, viele Jahre lang über diese faszinierende Klasse kolloider Systeme, die Seifen, zusammengearbeitet und durch Ihre Anregungen und Ihre Hilfe die wissenschaftliche Kolloid-Chemie der Seifen vielfach und wesentlich gefördert. Das ist aber nur eine Seite. Sie haben systematisch und konsequent diese wissenschaftliche Erkenntnis angewandt und ausgewertet, so weit dies nur möglich war, auf die zahlreichen, rein praktischen Fragen der Seifenfabrikation. Sie haben bewußt und mit erheblichen Erfolgen versucht, die Fabrikation der Seifen auf die ihr zugehörige wissenschaftliche Basis, nämlich auf die kolloidchemische Basis, zu setzen, und Sie sind in dieser bewußten wissenschaftlichen Durchdringung einer typischen Kolloid-Industrie beispielgebend gewesen."

Arthur Imhausen besaß die glückliche Gabe, wissenschaftliche Erkenntnisse in die Praxis zu übertragen. Zahlreiche Verfahren und Patente zeugen davon. Im Jahre 1934 nahm er gemeinsam mit seinem Sohn die Arbeiten über die Herstellung synthetischer Fettsäuren durch Oxydation von Kohlenwasserstoffen wieder auf. Er fand die Lösung zur Errichtung einer Großanlage.

Durch dieses Arbeitsgebiet kam er zwangsweise in Berührung mit anderen Zweigen der Chemie. Nebenprodukte mußten verwendet werden. Und so kamen er und sein Sohn, Karl Heinz Imhausen, in andere Richtungen der Forschung und Produktion, so daB aus einer Seifenfabrik ein chemisches Werk mit umfangreichem Arbeitsprogramm und vielseitigen Produktionsstätten wurde. Arthur I m h a use n hat bis kurz vor seinem Tode die Richtung gewiesen für den Aufbau dieses Unternehmens und damit die Basis für die Entwicklung gegeben.

Arthur $\operatorname{lm}$ hausen stellte seine Erfahrungen und Kenntnisse auch der Wirtschaft zur Verfügung. Er war Mitglied zahlreicher Verbände, von 1921-1933 Mitglied der Industrie- und Handelskammer Bochum, deren erster Nachkriegspräsident er wurde.

Mit Arthur Imhausen ist ein Mann von uns gegangen, der Pionier war auf seinem Gebiet. Er hat die Entwicklung der Seifenindustrie aus einem Gewerbe zu einer auf wissenschaftlicher Basis betriebenen Industrie entscheidend mit beeinflußt.

Die Kolloid-Gesellschaft wird ihrem Gründungsmitglied, dem langjährigen Mitglied ihres Vorstandsrates sowie ihrem großen Freund und Förderer stets ein ehrendes Andenken bewahren. 